Meta

Journal des traducteurs

Translators' Journal

\title{
Arabic Methaphor and Idiom in Translation
}

\section{Mohammed Menacere}

Volume 37, numéro 3, septembre 1992

URI : https://id.erudit.org/iderudit/003627ar

DOI : https://doi.org/10.7202/003627ar

Aller au sommaire du numéro

Éditeur(s)

Les Presses de l'Université de Montréal

ISSN

0026-0452 (imprimé)

1492-1421 (numérique)

Découvrir la revue

Citer cet article

Menacere, M. (1992). Arabic Methaphor and Idiom in Translation. Meta, 37(3), 567-572. https://doi.org/10.7202/003627ar

\section{Résumé de l'article}

On étudie les difficultés de traduction des textes arabes empreints de concepts culturels. On démontre que les différences culturelles constituent une source importante de difficultés lors de la traduction arabe-anglais. Ces difficultés surgissent de comportements propres à chaque culture ou encore de différences d'interprétation des mêmes concepts. On traite également des possibilités de conservation des métaphores et des locutions arabes dans la traduction anglaise.
Ce document est protégé par la loi sur le droit d'auteur. L'utilisation des services d’Érudit (y compris la reproduction) est assujettie à sa politique d'utilisation que vous pouvez consulter en ligne.

https://apropos.erudit.org/fr/usagers/politique-dutilisation/ 
ARABIC METAPHOR AND IDIOM IN TRANSLATION

Résumé

On étudie les difficultés de traduction des textes arabes empreints de concepts culturels. On démontre que les différences culturelles constituent une source importante de difficultés lors de la traduction arabeanglais. Ces difficultés surgissent de comportements propres à chaque culture ou encore de différences d'interprétation des mêmes concepts. On traite également des possibilités de conservation des métaphores et des locutions arabes dans la traduction anglaise.

\section{SUMMARY}

This paper attempts to discuss the problems of translating Arabic discourse involving specific cultural concepts. Cultural differences besides linguistic complexities constitute areas of potential difficulties in translating Arabic into English. These difficulties arise when one form of behaviour in one culture is virtually non-existent in another, or when the same cultural concept is conceived and interpreted differently by both cultures. The paper also considers the degree to which Arabic metaphors and idioms may be preserved in English translation.

\section{TRANSLITERATION TABLE}

In this paper, Arabic is represented phonetically. Since there is virtually no standardized system of transliteration for Arabic script, the transcription used here follows basically the I.P.A. system with the following modifications:

$\begin{array}{lll}\text { th } & \text { instead of } & 0 \\ \mathrm{dh} & \text { instead of } & \delta \\ \mathrm{j} & \text { instead of } & \mathrm{d} \\ \mathrm{kh} & \text { instead of } & \boldsymbol{X} \\ \mathrm{gh} & \text { instead of } & \gamma \\ \mathrm{sh} & \text { instead of } & \mathrm{J} \\ \mathrm{S} & \text { instead of } & \tilde{z}\end{array}$

In the transcription of Arabic, there was a need to introduce other features to distinguish between certain sounds:

$\begin{array}{ll}\mathrm{DH} & \text { to represent } \\ \mathrm{T} & \text { to represent } \\ \mathrm{Dh} & \text { to represent } \\ \mathrm{H} & \text { to represent } \\ \mathrm{q} & \text { to represent } \\ 3 & \text { to represent }\end{array}$
is
$b$
$\theta$
$\varepsilon$

Short vowels: /a / for fat-ha, / $/$ / for DHama, / i / for Kasra

Long vowels: $\bar{a}$

FULL TRANSLITERATION TABLE

a

b

$t$

th

j

h

kh

d

dh

$r$

$\boldsymbol{z}$

$\mathbf{s}$

sh

S i

$\mathrm{DH}$

$\omega \quad \mathrm{T}$

$\ddot{D}$ Dh

$\therefore \quad 3$

$\varepsilon$

$\dot{\varepsilon}$

飞 gh

乙 $\mathrm{f}$

$\dot{z} \quad$

$>\quad k$

d)

$j$

$J$

$\dot{0}$

$\theta$

w

H

9

$s$

$\ddot{b}$

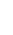

ह

i

$\ddot{*}$

$J$

r

$\infty \quad y$

$b$ 


\section{INTRODUCTION}

Although the modern trend of writing adopted by Arab writers is to keep metaphoric usage to the minimum, preferring an objective and neutral mode of expression, nevertheless, the Arabic language still makes use of some of the most "nuanced" vocabulary and expression instead of common concepts, objects, descriptions, etc. Metaphors can be defined as certain expressions which stretch their semantic values beyond their implicit areas of meaning. It is a process of referring figuratively and emotively to an object in terms of another, and the terms metaphoric and figurative are used almost interchangeably in this paper. Metaphor does not lead directly to the intended meaning because words in their contexts carry either a primary sense or secondary (figurative) sense.

Idiom and metaphor can be said to be similar as they both involve the figurative use of the language. In most cases, idiom and metaphor constitute an area of great unpredictability for the translator. It is an area of language which McEldowney (1981:5) calls

an abstract and more sophisticated area of language...

For Beckman and Callow (1974:127), metaphor is:

An implicit comparison in which one item of the comparison (the image) carries a number of components of meaning of which usually only one is contextually relevant to and shared by the second item (the topic)

For Newmark (1982:84), the purpose of metaphor is:

to describe an entity, event or quality more comprehensively and concisely and in a more complex way than is possible by using literal language.

\section{THE MEANING OF METAPHOR}

Naturally, the authors of the original texts draw on their own cultures for the images and figurative senses they use. The transfer of such images in the target language is likely to be unfamiliar. There is no consensus among translators as to how to approach metaphor. Some claim that metaphor should be rendered literally. Arnold and Sadler (1987:10) assume that:

metaphors are universal and thus translated literally.

Others contend that this process will lead to a meaningless result in the target text. For instance, Nida believes that:

metaphors must be translated as non-metaphors.

Pergnier (1980:248) goes even further to state that:

whether lexical or grammatical, idioms and metaphors in any case appear to be impossible to translate analytically.

(Translated from French by the present writer)
It can be argued, that each language has its own way of distributing metaphors to cover semantic fields. Since metaphors have deviant meaning, one of the aspects of the target language culture that the translator of Arabic needs to be aware of is the degree of tolerance in English for unfamiliar and unusual collocations. Any attempt to carry over the artifacts of so alien a culture into English implies a certain cultural transparency.

The effectiveness of metaphor translation depends as much on our knowledge of the world of the target language as on our linguistic skills. The translator who approaches metaphor literally and is unable to go beyond the deviant usage will often fail to achieve an adequate translation. The potential for several equivalents a metaphor may have, may be reduced by analysing it in discourse i.e. evaluate its communicative purpose in discourse, and the context of use can guide the translator to a better understanding, thereby restricting the openness of meanings in the metaphor. Culturally, Arabic and English differ considerably, thus it is wrong to assume that the transmission of current practice and use of metaphors of Arabic are always welcome in English. Flexibility and sensitivity are needed by the translator handling the many instances of metaphor; sensitive to the impact his translation is going to have on the English reader and flexible in approaching a sophisticated area of language.

Consider the use of some metaphors in Arabic and how their deviant meaning in translation is accounted for:

1. tajri: alisti3dadat 3ala qadam wa sāq (lilintikhabat)

Considered literally the sentence in English is nonsensical: "The preparations are going on foot and leg (for the elections)."* For the sense to emerge and in order to obtain a closer equivalent, analysis and modifications are necessary. The following translation may be suggested: "Preparations for the elections are in full swing."

2. qatala almawDHu:3a bahthan

Literally, this is translated as "he killed the topic with research."* The implicit meaning carried by the metaphor is absent, that is "to study or investigate the topic thoroughly."

3. qatala adaHra khibratan

Literally, this is translated as "he killed time with experience,"* so once again rewording and restructuring to reproduce the Arabic metaphor is almost inevitable if the meaning is to be achieved.

It can be noted here, that the reliance of English on lexis is deeply felt in discourse. This lexis is highly specialized and extremely well-developed with items often showing narrow collocational ranges. Arabic with its inflectional nature, on the other hand, shows a predominance of grammatical elements. Notice the grammatical markers in examples 2 and 3 above: bahthan and khibratan. These are "masadir" (sing. 
"masdar") (nouns) with adverbial functions. As we are interested in the communicative value of these language items in translation and the difficulty of transferring them accurately, rather than undertaking a grammatical analysis, it is sufficient to say that bahthan and khibratan are lexemes which consist of a "masdar." The term "masdar" is literally "source" i.e. it refers back to the paradigm or pattern from which the words are derived, that is bahth and khibrat suffixed to the morpheme an.

One word metaphors are often easier to translate. For instance:

a) laysa laHu qadam fi almawDHu:3

which rendered literally means "he has not a foot in the matter."* This roughly has the English equivalent "he has no say in the matter."

b) hablu atafkir

that is, the "rope of thought"* whereas in English it is the "thread of thought."

c) yaskunu fi ahDHani asahrāa

literally meaning "he lives in the bosom of the desert," whereas English might say "he lives in the heart of the desert." This Arabic metaphor also embodies a sense of an embrace and welcome within the desert rather than the sense of hostility and hardship often associated with the desert by those unfamiliar with such regions.

Arabic newspapers like the rest of the world's papers, use metaphors profusely for the purpose of effect and sensationalism, e.g.:

ishta3alat aljabaHāt min jadi:d fi alkhali:j

literally translated as "in the Gulf, the fronts are ablaze once more," or

anajm alarjantini:alfadh maradona

literally translated as "the unique, extraordinary, Argentinian football star Maradona."

mushkilat rusiya Hiya alkhuru:j min almustanqa3 alafghäni:

literally translated as "the Russian problem is the withdrawal from the Afghan swamp."

This frequent use of metaphor is true of Arabic discourse generally which tolerates a higher density and frequency of metaphoric usage than English. Although metaphors such as these appear regularly in the tabloid press, this frequency is not true of English discourse generally and thus poses difficulties in translation, English being less permissive. It can be argued, however, that a discourse analysis approach which takes into account both the linguistic features and the communicative purpose enables the translator to adjust and reconstruct the SL text according to the TL discourse norms.

\section{DEGREE OF TRANSLATABILITY OF ARABIC METAPHORS INTO ENGLISH}

It can be argued that Arabic is a more receptive and flexible language and is not hostile to foreign imagery and concepts. Loan metaphors stemming from English and French expressions have been adopted by Arab writers and journalists through the years of contact and thus these metaphors have established themselves in some texts as modern Arabic expressions. The question remains whether the two equivalent metaphors enjoy the same linguistic value in their respective languages. Consider the following examples:

1. to swim - yusāyiru atayāru a13ām the tide (follow) (the tide) (the general)

2. the symptoms of a new crisis a $3 r \bar{a} \mathrm{DH} u$ azmatin jadidat (symptoms) (crisis) (new)

3. a definite swing in favour of $\begin{array}{lll}\text { maylun } & \text { wāDHihun } & \text { nahwa } \\ \text { (inclination) } & \text { (obvious) } & \text { (towards) }\end{array}$

4. he gave the green light a3tā aDHua alakhDHari (he gave) (the light) (the green)

5. Dans le cadre de la visite - fi iTäri aziyārati $\begin{array}{ll}\text { (...from the French) } & \text { (in) (frame) (the visit) }\end{array}$

At first glance, some of the borrowed expressions in Arabic seem to match effectively in terms of semantic and stylistic values while others appear conspicuously strained and unnatural. If the borrowed expressions are translated back into English or French, some will pose no transfer problem while others will be barely recognizable in their respective languages. This sentence from a Saudi newspaper exemplifies this:

ziyāratu almalik faHd adhābat aljali:d fitari:q (visit) (King Fahd) (melted) (the frost) (in the way) i3ādat alßalaqāt bayna almaghrib wa aljazãir (resumption)(relations) (between)(Morocco and Algeria)

The common English metaphor "to break the ice," becomes in Arabic "to melt the frost." It can be argued, that this change of metaphor may be linked to climatic conditions i.e. Arabs are perhaps more familiar with the idea of frost melting than the breaking of ice. This degree of conflict in translating Arabic metaphors into English needs closer examination.

The use of symbols appears to have universal applications. For instance, symbols such as mother, earth, darkness, evil, etc., have more or less equal stands in both English and Arabic. The notion of duty whether to God, family or society is much more frequent in Arabic texts than in English. A sense of patriotism is much more linked with the view of Arabic as the language of national heritage than English, and reference to religion is much more common in Arabic. The difficulty of handling these "topics" in translation lies in the excessive use of 
language i.e. overstatement, and in the different attributes to the same topic by the two languages. While English often emphasizes rational and nonemotional use of imagery, Arabic shows excessive use of metaphors which might not match the conceptual and expressive patterns of English, for example:

\section{hawama biH alfikr fi awdiyat shata}

which rendered literally means "his thoughts were scattered over many rivers,"* that is "many things raced through his mind."

\section{ashba3aHu DHarban}

which rendered literally means "to satisfy his appetite with a beating."* This can be expressed in English by "he was given a good hiding."

\section{fi kabidi asamaa}

meaning literally "in the liver of the sky"* It is interesting that in Arabic, the word "liver" symbolizes strong feelings, especially of endearment. It is common to talk of one's child as kabidi: (my liver). This contrasts sharply with English where the term "liver" is associated with bile and bitterness, and where someone who is "liverish" is peevish or glum.

The transfer of such expressions is beyond any bilingual dictionary because a straightforward rendition without comprehension and analysis of discourse appears stretched and unnatural in English. This demonstrates further the discrepancy on the level of emphasis and metaphor between Arabic and English. The information contained in the above metaphors aims at enhancing the effect of the message, but they do not carry the same function once they are transferred into English. This is clearly illustrated by the following example:

\section{quwätuna arābiDHa 3ala alhudu:d}

which can be translated as "our forces guarding the frontiers." The word rabaDHa, however, carries a different meaning than suggested by the translation. Although difficult to explain verbally, it means "the movement made to lie down with the chest to the ground," in the way an animal such as a camel goes to lie down to sleep. It is almost impossible to find an equivalent in English which conveys this image, which was intentionally used in Arabic. If the original meaning had been simply of "guarding the frontiers" the following expression would have been used:

\section{quwātuna tahrusu alhudud}

When symbols convey different meanings in the two languages, a complete transformation of the metaphor is necessary if the translation is to make sense. For instance, the "animal field" provides numerous examples of conflict. An "owl" in Arabic is an omen of doom and gloom, whereas in English it is the symbol of wisdom. A "dog" is a contemptible animal and a derogatory term in Arabic, and though it is not alto- gether devoid of an abusive sense in English, e.g. "dirty dog," it is still regarded as a symbol of faithfulness and man's best friend.

The extent to which a metaphor can be adopted in English depends on its importance for the transmission of the textual meaning. If the translator considers the transfer of metaphor as alien and redundant, he may be justified in leaving it out to make the target language communicative and acceptable to the reader or he may decide to bring out "native colour" which is remote and an entirely different world of expression and thought. In any case, the translator's dilemma remains how to convey meaning accurately across the barrier of cultural differences.

\section{IDIOMS}

Idioms belong to a sophisticated and abstract area of language where meanings are fixed. The difference between idiomatic and metaphorical expressions can be said to be that in idiomatic expressions, the words transmit rather than illustrate the meaning, in metaphorical expressions the words "colour" the meaning. Idioms vary in their function and value and the loss of effect in discourse in translation can be considerable. Idioms and "prefabricated" patterns present special problems for the translator because they contain more than one word but form a single unit of meaning.

One of the major obstacles in the translation of idioms is determining the exact emotive and aesthetic meaning of the idioms or clichés which are often of a vague and ambiguous nature, particularly in some discourse types. Consider the following, for instance:

$\begin{array}{lll}\text { 1. } \begin{array}{ll}\text { tußadu } \\ \text { bayna }\end{array} \text { aljazăir } & \text { algharb wa asharq } \\ \text { (regarded) } & \text { (Algeria) } \\ \text { (between) } & \text { (west and east) }\end{array}$

this is, "Algeria is regarded as a bridging point between West and East."

$\begin{array}{lllll}\text { 2. akala 3alayH } & \text { adaHr } & \text { wa } & \text { sharib } \\ \text { (ate) (on it) } & \text { (the time) } & \text { (and) } & \text { (drank) }\end{array}$

that is, "to be old and worn out."

3. Turiha almawDHu:3 3ala biSāT

albahth

(cast) (the issue) (on) (the carpet)

(of the discussion)

this is, "to raise the question for discussion."

These few examples of widely-used expressions reveal the linguistic as well as the cultural divergence between the two sets of idioms. Ideally, the familiarity and frequency of the well-established idioms in Arabic discourse whould be translated as far as possible with an idiom equivalent in English. In the case of lack of equivalence, it would be "reckless" to attempt a word for word translation. For example, the expression: 


\section{zu:r ghiban tazdad huban}

if translated literally means "visit rarely and you will be loved more." The illocutionary force carried by the words ghiban and huban come out weaker in literal translation. Because of their inflectional nature, Arabic words imply more than surface meaning. Instead of transferring the above expression into an explicit and simplistic statement, it seems more appropriate to offer the following equivalent: "Absence makes the heart grow fonder." A reasonable approach, therefore, is to try to understand the idiom, interpret its meaning and transfer the meaning in the target language.

\section{DEGREE OF NON-EQUIVALENCE}

Since language is part of culture, it is inevitably influenced by social-cultural factors such as tradition, behaviour, dress, food, etc. It can be argued, that in terms of translation, an Arabic discourse texture which stands poles apart from English will yield unusual collocations of words and phrases. By collocations it is meant the co-occurrence of words in specific utterances. This important aspect of discourse constitutes a challenging aspect of language in translation. This point is stressed by McGuire (1980: 34):

In so far as language is the primary modelling system within culture, cultural untranslatability must be de facto implied in any process of translation.

\section{Consider the following examples in English:}

bread and butter, bed and breakfast, rack and ruin, thick and thin, etc.

These common collocations are natural to any English speaker because they portray English customs and ways of life, but if translated literally into Arabic would be "exiled" and meaningless. Similarly, Arabic collocations mismatch and appear strange in English. For instance:

tamrun wa hali: $b$ (dates and milk)

abun 3 an jad (grandfather to father)

alfahsha-u wa almunkar ( $\sin$ and the forbidden), etc.

These examples do not present insurmountable obstacles because they have referential meanings i.e. they operate within well-established boundaries. Still they can appear watered-down in paraphrased English and their impact is reduced. This is particularly true of collocations of words which are linked not only by associated meaning but also by rhythm and alliteration, for instance

alhasab wa anasab
$\begin{aligned} & \text { - of noble birth and } \\ & \text { descent }\end{aligned}$
$\begin{array}{ll}\text { lahmun wa dam } & \text { - flesh and blood } \\ \text { sama3an wa ta3atan } & \text { - I hear and I obey }\end{array}$

It is rare to find an example such as

$$
\text { ghamun wa Ham - gloom and doom }
$$

where the two sets of collocations echo each other in meaning and in rhythm as the linguistic interplay is often irretrievable in translation.

Arabic discourse shows a process of thinking largely bound up in the language habits of its community. This predisposes certain choices of interpretation. The large spectrum of the influence of culture on the production and language communication raises the question of translation limitations. For instance, the frequency of greetings, the expressions of good will, the lexical analysis among human emotions such as fear, hope, apprehension, gratitude, etc., which are closely related to experience and events, all these emotions have in Arabic a religious slant. There is resignation to God and God used as a "shield," guardian, protector, etc., $Y a$ allaH, bi ismallaH, in shallaH, etc., trust and reliance on God (tawki:l), naming of God (basmala), oath (yamin), fate and destiny (alqaDHaa wa alqadr) and so on. There is superstition or myth and fear from the forces of evil - the idea of "daHr" (fate), capricious and impossible to predict, setting the right time (ajal) for everyone's death, the owl bringing omens of death and calamity. There is the expression:

khamasa fi 3ayn al3aduw (five in the eye of the enemy)

five representing the five fingers of the hand, combining an oral and manual rite.

Such behavioural and communicative aspects of the discourse signify a subtle purpose and in translation they are often left out because of their alien nature. Other striking cultural differences lie in the description of certain feasts, rituals and traditions, for instance rainmaking rituals which are deeply rooted in religion and involve a special prayer known as "Salät alistisqāa" and is commonly held after long periods of drought. Descriptions of rituals such as circumcision, prejudices, eating habits, seating arrangements, patterns of events, and so on all present problems in the translating process.

\section{CONCLUSION}

The degree to which Arabic metaphors and idioms are preserved in English depends in large measure on the discourse type. If the communicative purpose of the discourse is to transmit and make known cultural concepts, the translator feels justified in retaining as many cultural features as possible. If the translation under consideration needs to be transmitted in such a way as to avoid creating a sense of alienation in the target language, however, the translator may be justified in omitting them. Thus, what the translator must take into account when dealing with these obscure areas of language is that he cannot translate what the reader cannot understand, but he 
must not be discouraged. He must organize his target discourse texture to convey communication exploiting all the possibilities open to him. The assessment of Arabic discourse in English is not judged by each item which must correctly match the other, but rather as a text carrying the same message and playing an identical role in English for the same action or event described, because even when the two cultures share the same cultural aspect, the establishment of linguistic components is always a matter of laborious and delicate readjustment.

\section{MOHAMMED MENACERE}

Tipaza, Algeria

\section{BIBLIOGRAPHY}

ARNOLD, D. and L. SADLER (1987): Working in Language Processing, University of Essex, unpublished paper.

BASNETT-McGUIRE, S. (1980): Translation Studies, London, Methuen and Co. Ltd.

BEEKMANN, D.J. and J. CALLOW (1974): Translating the Word of God, Grand Rapids, Zondervan Publishing House.

McELDOWNEY, P. (1982): English in Context, London, Thomas Nelson and Sons Ltd.

NEWMARK, P. (1982): Approaches to Translation, Oxford, Pergamon Press.

PERGNIER, M. (1980): Les Fondements sociolinguistiques de la traduction, Paris, Diffusion libraire Honoré Champion.

\section{A QUESTION ON TRANSLATION}

Techniquement, selon la définition de Roman Jakobson, le «poétique» (c'est-à-dire le littéraire) désigne ce type de message qui prend sa propre forme pour objet, et non ses contenus.

Roland Barthes, Le bruissement de la langue, Paris, Seuil, p. 15.

Jakobson's notion of the littéraire calls for a revision of the theory of language; therefore, of translation. Up to now, the problem of translation has been treated either from a semantical or from a syntactical point of view, - or a combination of both - within a text. By definition, a text is a set of properly organized language units, obviously, within a specific topic.

Consider as examples: James Joyce's Finnegans Wake and Samuel Beckett's Act without Words. We have then, two different literary works: one, we call a novel, the other a play (a play to be acted out, not to be talked). 